\title{
PRODUCTIVE ENGAGEMENT AMONG COMMUNITY-DWELLING ELDERS OF SRI LANKA
}

\author{
RASP Ranabahu ${ }^{1}$
}

\section{Abstract}

Productive engagement is the involvement of older adults in society through employment, volunteering, and caregiving (Morrow-Howell and Mui, 2012). Although the unprecedented growth of elderly population in the Sri Lanka's age structure remains a long-term challenge for the country, the positive ageing discourse puts forward the perspective that capacity of independent, healthy and active older people must be promoted and utilized to make them contribute to the society through various productive activities. The current paper attempted to examine the nature of engagement and their effects on elders, using a sample of 350 community-dwelling elders in three geographical settings representing urban, rural and estate sectors of Sri Lanka. The study was guided by the pragmatic paradigm and used mixed-methods design with a deductive theoretical drive. The results highlight the current state of engagement in each of the three productive activities explaining across personal attributes of elders. The perceived benefits of engagement are summarized and opportunities and barriers are noted to assist future transformations pertaining to productive ageing policies and programmes in Sri Lanka.

Keywords: Caregiving, Elderly population, Paid work, Productive engagement, Volunteering
${ }^{1}$ Department of Geography, University of Ruhuna

shyama.ranabahu@gma il.com

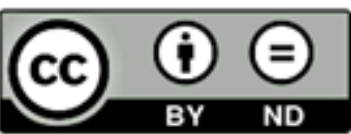

This article is published under the Creative Commons CC-BY-ND License (https://creativecommons.org/licenses/by-nd/4.0/). This license permits use, distribution and reproduction, commercial and non-commercia, provided that the original work is properly cited and is not change anyway. 


\section{INTRODUCTION}

Population ageing is the most prominent global demographic issue of the $21^{\text {st }}$ century. The unprecedented growth of the elderly population is seen in the Sri Lanka's age structure and therefore, it has become one of the leading demographic issues in our country too. According to the World Bank (2008), Sri Lanka is rated as the country with the fastest ageing population in the South Asian Region. Sri Lanka's share of the older population was 12.4 percent in 2012, a rapid increase from 6.3 in 1971 and projected to be reached up to 24.8 percent in 2041 (Department of Census and Statistics, 2012).

Although, the proportion of elders tend to increase in the world, considering an elder 'as a valuable resource' is yet to be established. The common stereotypes are usually negative that leads to subjective, biased image of older persons being useless, weak or dependent (FernandezBallesteros et al, 2011). They are also viewed as the receivers of social support rather than the providers or contributors to the society (Van der Meer, 2006). However, World Health Organization (2002) proposes that population ageing is one of the humanity's greatest triumphs, while it is one of the greatest challenges too. With people living longer than ever before, remaining healthy until later years than in the past, society has an opportunity to reap a "longevity dividend" in which older people continue to make a substantial contribution for long periods (Beard et al., 2012). While the negative and profoundly inaccurate stereotypes of elders being challenged over time, a potential mechanism for amplifying the benefits and ameliorating the challenges of an ageing population is to promote positive ageing practices which support elders to remain independent, healthy and active as they age. The existing literature on ageing across various disciplines emphasizes new paradigm of the positive aging process which is termed as 'active ageing', 'healthy ageing', 'successful ageing' or 'productive ageing'.

Research has also shown that elders continue to make valuable contributions to their own family and to the community by engaging in various activities even after they withdraw from the labour force. They have identified specific forms of activities elders engaged in during their old age and classified them as 'productive activities' (Herzog et al., 1989; Bass and Caro, 2001; Caro et al., 2005; Fernandez-Ballesteros et al., 2011). According to Bass, Caro and Chen (1993), productive activity refers to "any activity by an older individual that contributes to producing goods or services, or develops the capacity to produce them, whether they are to be paid for or not". Research has shown that some of these activities provide economic value, but they also provide important social benefits too. Since the concept of 'productive ageing' draws attention towards a broader perspective of contributions made by elders outside paid work, it is important to focus investigations on unpaid contributions which ensure the capacity to be engaged with their families and their communities.

Scholars have identified various forms of productive activity. Caro et al. (2005) identified activities such as work, volunteering, taking care of a sick relative, babysitting for grandchildren, taking classes and exercising while FernandezBallesteros et al. (2011) categorized them as; self-care, leisure activities, paid work and unpaid productive work. The literature, therefore, does not have any consensus about activities that are productive or not. The activities which influence healthy and active lifestyles of elders are being considered as productive 
because the existing literature reveals that being active and engaged in old age is continuously being identified as having a beneficial effect on them (Walker, 2002; Avramov and Masakowa, 2003; Cloos et al., 2009; Fernandez-Ballesteros et al., 2011; Morrow- Howell and Mui, 2012; Sidorenco and Zaidi, 2012; Wiles \& Jayasinha, 2013; Morrow - Howell et al., 2015).

\section{RESEARCH PROBLEM}

Since population ageing poses many challenges for Sri Lanka, the positive perspectives towards elderly should be strengthened to absorb and value the contributions made by elders to the community. The main issue raised is, how aged be helped to remain independent and engaged as they age? The abilities, experiences, expert knowledge and special skills of the elderly are needed in our societies. If ageing is to be a positive experience for the growing elderly population, their longer life must be of worth to themselves as well as to others. Hence, it is important to explore the resources and potentials of elders who are being engaged in various productive activities in the context of different spatial units in Sri Lanka. Since the definitions of productivity have many facets and meanings and the activities related to productivity has no consensus, three main activity domains were explored in this paper. They were paid work, volunteering, and caregiving.

The main objective of this paper is to explore the nature of productive engagement among community-dwelling elders of Sri Lanka. The specific objectives are, to identify the sociodemographic profile of elders and to examine the benefits of engagement. The paper also aimed to study the perceived barriers and opportunities of engagement in three residential sectors of Sri Lanka viz., urban, rural and estate.

\section{MATERIALS AND METHODS}

The study was guided by the pragmatic paradigm and used mixed-methods design with a deductive theoretical drive. The study locations were Sri Jayewardenepura Kotte Divisional Secretariat Division (DSD) in Colombo district (urban), Narammala DSD in Kurunegala district (rural) and Nuwara Eliya DSD in Nuwara Eliya district (estate). The study has started with the quantitative data collection method with the questionnaire survey, conducted with 350 community-dwelling elderly respondents which were drawn by a multi-stage random sampling method, to be followed by a qualitative data collection involving detailed exploration through 36 in-depth interviews. The quantitative methods helped in collecting data to measure the pervasiveness of elderly engagement and the patterns of association between various factors. Qualitative methods, on the other hand, allowed to understand the explanations of "why" and 'how' the phenomena occur and the range of their effects on elders. Mixed methods research, therefore, can be identified as not simply collecting quantitative or qualitative data but, as collecting multiple forms of quantitative and qualitative evidence (Creswell et al, 2010).

The current engagement of paid and unpaid work was explored through the question "Do you currently engaged in any paid activity? any volunteer activity? and any activity of care? The questions followed by a range of other questions to collect data and information on activity type, reasons for engagement and disengagement, benefits and other related issues. The spatial and gender differences have been investigated in terms of elderly engagement in various activity domains.

The variables were mainly emerged as ordinal and nominal which were analyzed using mixed method analysis. Due to discrete (categorical) nature of the 


\section{Original Article}

dependent and independent variables, bivariate analysis was performed as a method of assessment. Cross-tabulations were run for categorical and ordinal variables and Pearson's Chi-Square test was performed using the SPSS 21.0 to determine the association between select dependent and independent variables. The qualitative data was analyzed by thematic analysis and the results were used to complement the findings derived from the quantitative analysis. Through the qualitative analysis, a range of elderly perspectives and experiences could be derived and they were used to expand the scope of final results of this study.

\section{RESULTS}

\section{Socio-demographic Profille}

The mean age of respondents in this study was 70.5 years with a range of 60 to 90 years. Among the respondents, 57.4 percent were females; 76.3 percent were Sinhalese; 74.6 percent were Buddhists. About 54.6 percent were married while 39.1 percent were widowed. The majority $(62.6 \%)$ have up to secondary level educational attainment while 7.4 percent had no schooling. Majority of elders $(84.6 \%)$ were living with their own family and 76.3 percent were living in their usual place of residence i.e.. own family home environment. Out of them, 61.7 percent have been living in the place of residence more than 20 years while another 20.9 percent from birth. Majority of respondents in urban (Kotte) and rural (Narammala) study settings were of Sinhalese $(94.3 \%, 100 \%$ respectively) and Buddhist (92\%, 97.9\% respectively) origin while estate sector (Nuwara Eliya) has Tamil (87.8\%) Hindu (79.3\%) majority. In the case of educational attainment, comparatively higher percentage $(20.7 \%)$ of persons were reported without schooling in Nuwara Eliya while 44.1 percent of elders residing in the urban area (Kotte) have a higher educational attainment of above SSC.

\section{Engagement in productive activities}

The elderly engagement in three main productive activities viz. paid work, volunteering and activities of care were examined in the present study using a mixed methods research design. A paid activity in this study referred to any gainful activity which includes formal employment and any other selfemployment activity while volunteering is defined as involvement in activities related to professional, civic, political or religious organizations. The engagement in activities of care was considered as providing care and protection for any person (children or adults) both within and outside the family.

The present study revealed that 36.0 percent of elders were engaged in paid work at the time of the survey while the engagement in volunteering and activities of care was 57.4 percent and 35.1 percent respectively. Elderly engagement in three types of activity can be predicted by various personal characteristics such as gender, age, marital status, educational attainment and living arrangement. The Pearson Chi-square test was used to determine the relationship between variables and the results are indicated in Table 1. 
Table 1: Pearson Chi-square analysis of productive engagement for communitydwelling elders in Sri Lanka $(n=350)$

\begin{tabular}{|c|c|c|c|c|}
\hline Variable & Activity & $\chi^{2}$ value & df & $\mathbf{p}$ \\
\hline Gender & Paid work & 17.098 & $\overline{1}$ & $\overline{0.000}$ \\
\hline \multirow[t]{2}{*}{ (male, female) } & Volunteering & 1.977 & 1 & 0.160 \\
\hline & Activities of care & 5.506 & 1 & 0.019 \\
\hline Age & Paid work & 17.731 & 1 & 0.000 \\
\hline \multirow{2}{*}{$\begin{array}{l}\text { (young elderly, } \\
\text { old elderly) }\end{array}$} & Volunteering & 1.857 & 1 & 0.173 \\
\hline & Activities of care & 16.013 & 1 & 0.000 \\
\hline Marital Status & Paid work & 12.765 & 2 & 0.002 \\
\hline \multirow{2}{*}{$\begin{array}{l}\text { (never married, currently } \\
\text { married, other) }\end{array}$} & Volunteering & 19.987 & 2 & 0.000 \\
\hline & Activities of care & 11.007 & 2 & 0.004 \\
\hline \multirow{3}{*}{$\begin{array}{l}\text { Educational attainment } \\
\text { (no schooling, primary, } \\
\text { secondary, SSC, HSC } \\
\text { and above) }\end{array}$} & Paid work & 5.926 & 4 & 0.205 \\
\hline & Volunteering & 61.528 & 4 & 0.000 \\
\hline & Activities of care & 5.673 & 4 & 0.225 \\
\hline \multirow{3}{*}{$\begin{array}{l}\text { Living arrangement } \\
\text { (alone, with immediate } \\
\text { family, other) }\end{array}$} & Paid work & 5.593 & 2 & 0.061 \\
\hline & Volunteering & 2.992 & 2 & 0.224 \\
\hline & Activities of care & 8.429 & 2 & 0.015 \\
\hline
\end{tabular}

df - degrees of Freedom $\mathrm{P}<0.05$

Results indicate a significant gender disparity $(\mathrm{p}<0.001)$ regarding the engagement in paid work which comprised of more males $(57.1 \%)$ than females (42.9\%), indicating a male dominant participation pattern in the workforce after the age 60, while showing a female dominant engagement in the activities of care $(\mathrm{p}<0.05)$. However, in terms of volunteering, a significant gender difference could not be observed ( $p>0.05$ ). Figure 1 also illustrates the elderly engagement in productive activities by gender.

A considerable percentage of elders $(44.4 \%)$ were reported to be selfemployed in various forms of economic activities. There was 27.0 percent of elders who were engaged as labourers (which comprised of casual labourers, plantation labourers, and domestic workers) while about 15.0 percent of elders have engaged in agricultural work. The proportion of elders engaged in the fields of managerial, professional, technical and related were comparatively less (9.5\%). A gender difference can be observed with regards to the engagement of each occupation category. The majority of males have employed as labourers while the dominant paid activity of females was selfemployment. Almost 95.0 percent of elderly employees who were in the agricultural occupations were males.

The chronological age also has a significant association with the participation of elders in paid activities ( $p$ $<0.001)$ and activities of care $(p<0.001)$, but not for volunteering $(\mathrm{p}>0.05)$. However, the study noted that the majority of elders who had reported as being engaged at the time of the survey in paid work $(81.7 \%)$, activities of care $(81.0 \%)$ and volunteering $(70.6 \%)$ were in the 'young old' category. Even though the majority of elderly volunteers were young elders, there was a considerable percentage 
of old elders who perceived their involvement in the community.

This study demonstrates that marital status also has a significant association ( $p$ $<0.05)$ with the engagement in all studied productive activities. When compared with the currently non-married category, the currently married elders were more likely to be employed in paid work $(62.7 \%)$, volunteering $(64.7 \%)$ and activities of care $(49.8 \%)$. The findings have indicated that married elders were still in the process of caring for their families and even for adult children. Another interesting fact emerged in this study was that the female married elders were more involved in paid work after the age of 60 depicting their obligations towards family in spite of their elderly status. They have explained the need as "earning an extra rupee to help children", "cannot manage without having any income" and "do not want to be totally a burden to married children".

In this study, the educational attainment of elders does not seem to be a significant factor for determining the engagement in paid work or activities of care, although, more than 69.0 percent of elders who were involved in volunteer activities were observed as having at least secondary educational attainment. When the relationship between the elderly engagement and their living arrangement was explored, only the engagement in caregiving was observed as having a significant association $(\mathrm{p}<0.05)$ indicating that, the majority of elderly caregivers $(41.5 \%)$ were living with their spouses and children.

The study highlighted several salient features related to elders' role as caregivers. A total number of 123 elders had been identified as elderly caregivers in this study. They have mainly been providing care for their loved ones and it was interesting to note that, main care recipient from both male and female elders were grandchildren $(66.7 \%)$. Other than 'grand parenting', there was 26.2 percent of elders who were engaged in providing care and protection for other elderly persons such as their parents, parent-inlaws, siblings, and spouses.

\section{Elderly engagement in productive activities by residential sector}

A spatial difference can be identified with regards to the overall activity participation as illustrated in Figure 2 among elders of three residential settings. The figure highlights the fact that elders in rural areas were more involved with paid work and volunteering while indicating that caregiving was performed more by estate sector elders who reported low engagement in terms of paid work and volunteering. The lowest participation in paid work in this study was recorded among community-dwelling elders in the urban sector. The findings from the bivariate analysis using Pearson Chisquare test indicated a significant spatial disparity both in terms of paid work $\left(\chi^{2}\right.$ $(\mathrm{df}=2)=28.662, \quad \mathrm{p}<0.001)$ and volunteering $\left(\chi^{2} \quad(\mathrm{df}=2)=63.622, \mathrm{p}<\right.$ 0.001) among three residential sectors while not showing any relationship with regards to activities of care $\left(\chi^{2} \quad(\mathrm{df}=2)=\right.$ 2.230, $\mathrm{p}>0.05$ ).

Reasons and benefits of productive engagement

Elders in this study elaborated various reasons and benefits of engagement, both economic and social. The majority of elders have expressed that "in spite of various difficulties", they need to work even after being aged, in order to "meet the needs of the family". Despite their type of work and place of residence, they had indicated that the 'engagement in paid work' was an essential part of their old-age security. They have been engaging in various types of employment in need of money to fulfill various financial obligations. It was either for daily consumption or for other specific needs 
spouse's wellbeing etc. These results confirm the findings of Gaminiratne (2004) and Hettige (2014), which noted that many elders in Sri Lanka continue to remain economically active until later into their lives if they are in need of the financial assistance to survive during later years. WHO (2002) also confirms the fact that participation in an income-generating activity greatly influences one's financial readiness for old age.

According to the elders' perceptions, engagement in a productive activity has various positive effects on their lives. The majority of elders who had engaged in paid activities revealed that the engagement makes them busy and lively; independent; useful and connect them with outside world. The volunteering elders revealed that the engagement in societal activities assists them in developing relationships, contacts, and awareness on various issues. They also believed that regular connectedness with elderly peers helps them to dissolve their loneliness.

However, it was interesting to note that, mixed perceptions emerged when discussing with elderly care providers in terms of benefits and satisfaction gained from the engagement. They revealed that they were having mutually fulfilling relationships with their grandchildren, looking after them, watching them grow and being a part of their lives. However, the social and emotional aspects attached to the process of providing care for older adults were totally different. The elderly caregivers perceived that they were frequently impacted by caregiver strain when facing difficulties in fulfilling physical tasks related to the caring for other elders since their physical condition also tend to decline with age.

\section{SUMMARY AND CONCLUSIONS}

This paper has presented with the aim of highlighting the nature of productive engagement among community-dwelling elders in rural, urban and estate sectors in
Sri Lanka. The study noted that a significant percentage of elders were identified as being engaged in the selected productive activities in three residential sectors. It could also be identified that some elders tended to be engaged in multiple activities and was living in highly active lifestyle during old age. The findings noted the unpaid contributions of elders within the family in terms of both caring for grandchildren and providing long-term care for other elders. The personal attributes such as gender, age, and marital status have found to be associated with the engagement in paid activity and caregiving in this study. It was noted that educational attainment along with marital status has depicted a significant relationship with the engagement in volunteer activities. The caregiving was influenced by the living arrangement of the elders too.

The elderly volunteering has been observed as having limited opportunities and alternatives. The volunteer activities engaged by the elders in this study were confined to engagement in societal activities. The village elderly committees and other religious, professional and political organizations are the main avenues for community participation. On the other hand, a higher disengagement from productive activity was also could be identified among elders in this study. While 64.0 percent of elders were disengaged from paid work at the time of the survey, the disengagement in volunteering and activities of care was 42.6 percent and 64.9 percent respectively. Some of them tended to disengage from productive tasks mainly due to being perceived as too aged, or because of own health issues. There were some instances where elders have withdrawn from social engagement due to the separation from the spouse and after their involuntary mobility from the usual place of residence. Some elders who had temporarily moved from their usual residence were reported to be 


\section{Original Article}

confused and thus, stopped their usual activities. Some elders have become dependent on the unfamiliar surroundings because of their inability to orient their behaviours.

It could also be identified that volunteering has largely benefitted well- resourced elders with financial security, higher educational attainment, and more social contacts. A question, therefore, emerges as to how the resource-limited elders would be encouraged into productive social engagement in a context where they need to have a paid employment in order to survive. How does the gender equality be maintained? How can low-income, loweducated and less healthy elders be included in the broader dimension of productive engagement initiatives? Sri Lanka while enacting the Protection of Rights of Elders Act No. 9 of 2000 has made some provisions for encouraging elderly participation in the community. However, the elderly contribution might be increased to the benefit of communities, families, and elders themselves. Thus, the time has come to develop and strengthen long-term policies that build capacity across life course to support the productive engagement of elders.

\section{Figure 1: Elderly Engagement in productive activities by gender}



Source: Field Survey, 2013 
Figure 2: Elderly Engagement in productive activities by residential Sector

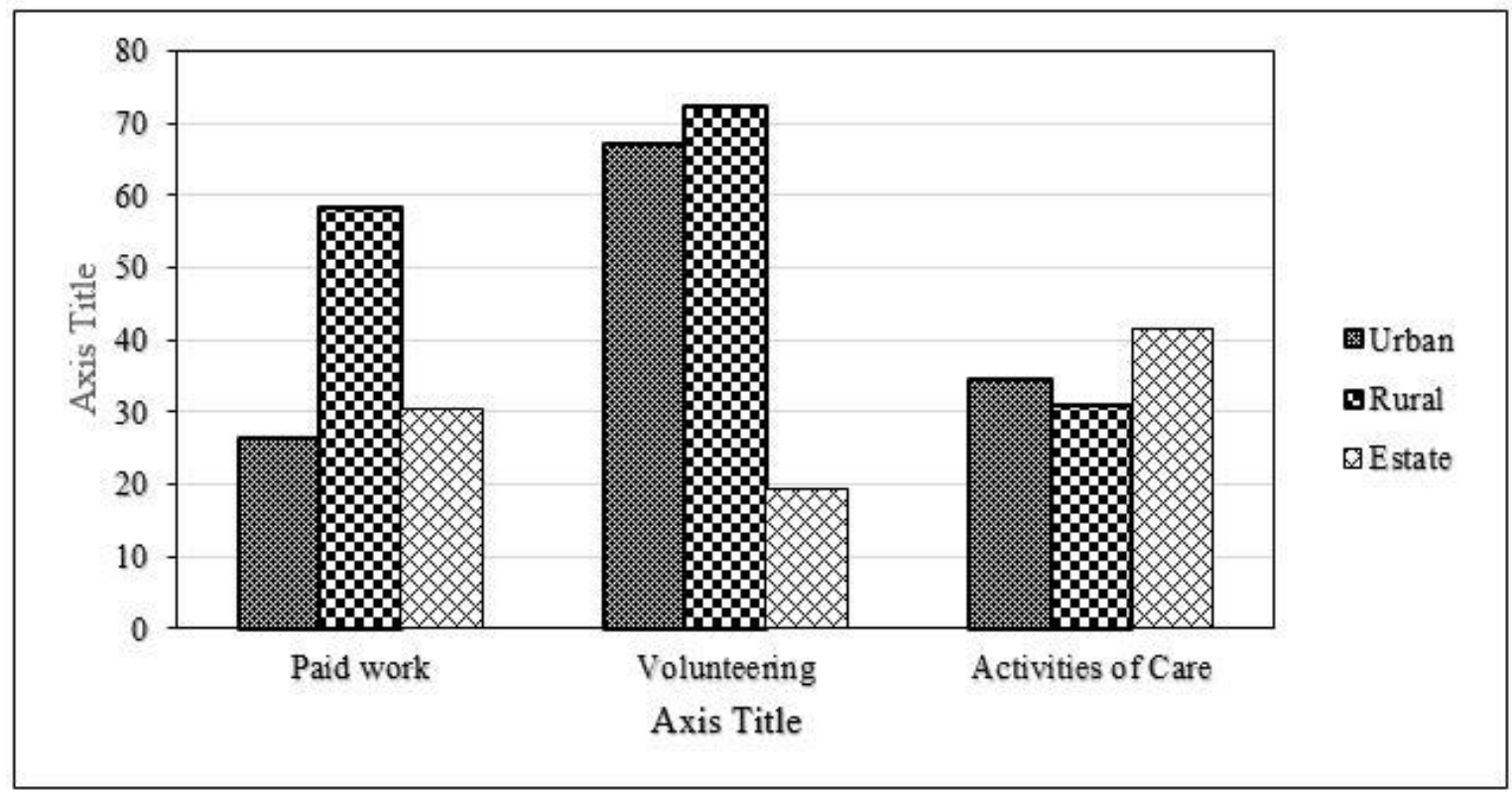

Source: Field Survey, 2013

\section{REFERENCES}

Avramov, D. and Maskova, M. (2003)

Active ageing in Europe,

Population Studies, No 41, Volume

1, Council of Europe.

Bass, S.A.; Caro, F.G. and Chen, Y.P. (1993) Theoretical Perspectives on Productive Ageing, In Crown, W.N. (eds) Handbook on employment and the elderly, Westport, CT: Greenwood Press.

Bass, S.A. and Caro, F.G. (2001) Productive Ageing: a conceptual framework In Morrow-

Howell N.; Hinterlong J.; Sherraden M. (eds) Productive Ageing: Concepts and Challenges, the John Hopkins University Press.

Beard, J.; Biggs, S.; Bloom, D.; Fried, L.; Hogan, P.; Kalache, A. and Olshansky, J. (2012) Global Population Ageing: Peril or Promise? Program on the Global Demography of Ageing, Working paper No 89, Harvard Initiative for
Global Health, Harvard University, Boston.Available at: http://www.hsph.harvard.edu/pgda/ working.htm

Caro, F.G.; Bruner-Canhoto, L; Burr, J. and Mutchler, J. (2005) Motivation for Active

Ageing: Results of a pilot study, Gerontology Institute, University of Massachusetts, Boston.

Cloos, P.; Allen, C.F.; Alvarado, B. E.; Zunzunegui, M.V; Simon D.T; Eldemire-Shearer, D. (2009) 'Active ageing': a qualitative study in six Caribbean countries, Ageing \& Society, 30(1), Cambridge University Press.

Creswell, J.W.; Klassen, A.C.; Clark, V.L.P.; Smith, K. C. (2010) Best Practices for Mixed Methods Research in the Health Sciences. National Institute of Health.

Department of Census and Statistics (2012) Population Census, Colombo, Sri Lanka 
Fernandez-Ballesteros, R.; Zamarron, M.D.; Diez-Nicolas, J.; Lopez bravo, M.D.; Molona, M.A.; Schettini, R. (2011) Productivity in Old Age, research on Ageing, 33 (2) Sage Publications $205-226$

Gaminiratne, N. (2004) Population Ageing, Elderly welfare and Extending Retirement Cover: The case study of Sri Lanka, working paper in www.odi.org

Hettige, S.T.(2014) Social Integration, Sustainable Livelihoods and Social Protection of Elders in Sri Lanka, Growing Old Gracefully, Human Rights Commissions of Sri Lanka and Helpage Sri Lanka.

Herzog, A.R.; Kahn, R.L.; Morgan, J.N.; Jackson, J.S. andAntonucci, T.C. (1989) Age Differences in Productive Activities, Journal of Gerontology, Social Sciences, 44: S129-38.

Morrow-Howell, N. and Mui, A.C. (2012) Productive engagement in Later Life, A Global Perspective, Routledge, London.

Morrow-Howell, N.; Gonzales, E.; MatzCosta, C.; Greenfield, E.A. (2015) Increasing Productive Engagement in Later Life, working paper no 08, Grand Challenges for Social Work Initiative, American Academy of Social Work and Social Welfare. Perspective, Routledge, London.
Sidorenco, A. and Zaidi A. (2012) Active ageing in CIS Countries: Semantics, Challenges and Responses, ed. FernandezBallesteros R., Current gerontology, and Geriatric Research, Vol. 2013, Hindawi Publication Corporation.

Van der Meer, M. (2006) Productivity among older people in the Netherlands: variations by gender and the socio-spatial context in 2002-03, Ageing Soc. 26, Cambridge University Press.

Walker A. (2002) A strategy for active ageing. (Second World Assembly on Ageing) International Social Security Review, Vol 55(1) pp 121-139

World Health Organization (2002), Active Ageing A Policy Framework, WHO, Geneva, Switzerland.

Wiles, J. L; Jayasingha R. (2013) the contribution older people make to their communities, Journal of ageing studies, 27(2013), Elsevier Inc. pp 93-101

World Bank (2008) Sri Lanka: Addressing the Needs of an Ageing Population, Human Development Department, South Asia Region, Washington, USA. 